\title{
RESEARCH
}

Open Access

\section{PET and CSF amyloid- $\beta$ status are differently predicted by patient features: information from discordant cases}

Juhan Reimand ${ }^{1,2,3^{*}}$ D, Arno de Wilde ${ }^{1}$, Charlotte E. Teunissen ${ }^{4}$, Marissa Zwan ${ }^{1}$, Albert D. Windhorst ${ }^{5}$, Ronald Boellaard ${ }^{5}$, Frederik Barkhof ${ }^{5,6}$, Wiesje M. van der Flier ${ }^{1,7}$, Philip Scheltens ${ }^{1}$, Bart N. M. van Berckel ${ }^{5}$, Rik Ossenkoppele ${ }^{1,8}$ and Femke Bouwman ${ }^{1}$

\begin{abstract}
Background: Amyloid- $\beta$ PET and CSF A $\beta_{42}$ yield discordant results in 10-20\% of memory clinic patients, possibly providing unique information. Although the predictive power of demographic, clinical, genetic, and imaging features for amyloid positivity has previously been investigated, it is unknown whether these features differentially predict amyloid- $\beta$ status based on PET or CSF or whether this differs by disease stage.
\end{abstract}

Methods: We included 768 patients (subjective cognitive decline (SCD, $n=194)$, mild cognitive impairment (MCl, $n=127$ ), dementia (AD and non-AD, $n=447$ ) with amyloid- $\beta$ PET and CSF $A \beta_{42}$ measurement within 1 year. Ninetyseven (13\%) patients had discordant PET/CSF amyloid- $\beta$ status. We performed parallel random forest models predicting separately PET and CSF status using 17 patient features (demographics, APOE4 positivity, CSF (p)tau, cognitive performance, and MRI visual ratings) in the total patient group and stratified by syndrome diagnosis. Thereafter, we selected features with the highest variable importance measure (VIM) as input for logistic regression models, where amyloid status on either PET or CSF was predicted by (i) the selected patient feature and (ii) the patient feature adjusted for the status of the other amyloid modality.

Results: APOE4, CSF tau, and p-tau had the highest VIM for PET and CSF in all groups. In the amyloid-adjusted logistic regression models, $\mathrm{p}$-tau was a significant predictor for PET-amyloid in SCD $\left(\mathrm{OR}=1.02\right.$ [1.01-1.04], $p_{\mathrm{FDR}}=$ $0.03), \mathrm{MCl}\left(\mathrm{OR}=1.05\right.$ [1.02-1.07], $\left.p_{\mathrm{FDR}}<0.01\right)$, and dementia $\left(\mathrm{OR}=1.04\right.$ [1.03-1.05], $\left.p_{\mathrm{FDR}}<0.001\right)$, but not for CSFamyloid. APOE4 (OR $=3.07$ [1.33-7.07], $\left.p_{\text {unc }}<0.01\right)$ was associated with CSF-amyloid in SCD, while it was only predictive for PET-amyloid in MCI $\left(\mathrm{OR}=9.44\right.$ [2.93, 30.39], $\left.p_{\mathrm{FDR}}<0.01\right)$. Worse MMSE scores $(\mathrm{OR}=1.21$ [1.03-1.41], $\left.p_{\text {unc }}=0.02\right)$ were associated to CSF-amyloid status in SCD, whereas worse memory $\left(\mathrm{OR}=1.17[1.05-1.31], p_{\mathrm{FDR}}=\right.$ 0.02 ) only predicted PET positivity in dementia.

Conclusion: Amyloid status based on either PET or CSF was predicted by different patient features, and this varied by disease stage, suggesting that PET-CSF discordance yields unique information. The stronger associations of both APOE4 carriership and worse memory z-scores with CSF-amyloid in SCD suggest that CSF-amyloid is more sensitive early in the disease course. The higher predictive value of CSF p-tau for a positive PET scan suggests that PET is more specific to AD pathology.

\footnotetext{
* Correspondence: jreimand@gmail.com; j.reimand@amsterdamumc.nl

${ }^{1}$ Department of Neurology \& Alzheimer Center Amsterdam, Amsterdam

Neuroscience, Vrije Universiteit Amsterdam, Amsterdam UMC, P.O. Box 7057,

1007 MB Amsterdam, The Netherlands

${ }^{2}$ Department of Health Technologies, Tallinn University of Technology,

Tallinn, Estonia

Full list of author information is available at the end of the article
}

(c) The Author(s). 2019 Open Access This article is distributed under the terms of the Creative Commons Attribution 4.0 International License (http://creativecommons.org/licenses/by/4.0/), which permits unrestricted use, distribution, and reproduction in any medium, provided you give appropriate credit to the original author(s) and the source, provide a link to the Creative Commons license, and indicate if changes were made. The Creative Commons Public Domain Dedication waiver (http://creativecommons.org/publicdomain/zero/1.0/) applies to the data made available in this article, unless otherwise stated. 


\section{Introduction}

Alzheimer's disease (AD) is characterized by the accumulation of amyloid- $\beta$ plaques, which has been shown to occur decades before symptom onset $[1,2]$. Amyloid- $\beta$ pathology can be detected in vivo by positron emission tomography (PET) using amyloid- $\beta$ radiotracers such as $\left[{ }^{11} \mathrm{C}\right]$ Pittsburgh compound-B (PIB), $\left[{ }^{18} \mathrm{~F}\right]$ Florbetapir, $\left[{ }^{18} \mathrm{~F}\right]$ Florbetaben, or $\left[{ }^{18} \mathrm{~F}\right]$ Flutemetamol allows to directly visualize fibrillary amyloid- $\beta$ deposits in brain tissue [3-6]. Alternatively, $A \beta_{42}$ levels in cerebrospinal fluid (CSF) reflect the concentration of soluble amyloid- $\beta$, which correlates with cerebral amyloid- $\beta$ depositions [7]. PET and CSF have been included as equal alternatives into diagnostic criteria for both research [2, 8, 9] and clinical practice [10-12], although they measure amyloid in different pools (i.e., CSF and cortical brain tissue). In addition, it has been repeatedly shown in memory clinic cohorts that in 10$20 \%$ of patients these modalities yield conflicting results [13-15]. In our previous work, we showed that PET/CSF discordance also inflicts patient prognosis and thus has potential clinical consequences [16]. This discordance may include valuable information on underlying clinical or neuropathological differences [17].

A combination of various patient features has previously been demonstrated to predict amyloid- $\beta$ positivity based on PET and/or CSF $[18,19]$. In particular, a combination of demographic information, APOE $\varepsilon 4$ carriership, neuropsychological tests, and magnetic resonance imaging (MRI) measures was effective in predicting amyloid- $\beta$ status [20]. Additionally, CSF tau and p-tau have been shown to be predictive of amyloid PET status [21]. So far it has not been investigated whether the predictive ability of patient features for amyloid- $\beta$ pathology differs when detected by PET or by CSF. We hypothesized that if there are significant differences in the predictive patterns of the two modalities, they must convey partially independent information. Additionally, as it has been suggested that CSF might be able to detect amyloid- $\beta$ depositions earlier [22], it is possible that the relative predictive contribution of a patient feature changes throughout the course of Alzheimer's disease. Therefore, in this exploratory study, we investigate the unique information provided by the PETCSF discordant population using the predictive patterns for amyloid PET and CSF in (i) the total patient group and (ii) stratifying by syndrome diagnosis. Exploring this allows us to gain insight in the clinical and neurobiological factors related to discordant results between amyloid- $\beta$ PET and CSF and ultimately about the underlying neuropathological processes during the disease course of AD.

\section{Methods}

\section{Study population}

We retrospectively included 777 patients, who had visited our tertiary memory clinic between 2005 and 2017 and had undergone both CSF $A \beta_{42}$ analysis and amyloid- $\beta$ PET within 1 year. We excluded nine patients that did not pass PET imaging quality control. Patients were screened according to the standardized protocol of the Amsterdam Dementia Cohort [23, 24]. This includes a clinical and neuropsychological evaluation, $A P O E$ genotyping, MR imaging, and lumbar puncture for CSF analysis. Patient diagnosis was determined during a multidisciplinary meeting, according to international guidelines [10, 11, 25-33].

\section{Neuropsychological testing}

Subjects underwent extensive neuropsychological testing as part of their diagnostic process. Mini-Mental State Examination (MMSE) scores were used to measure global cognition. In addition, five cognitive domains were assessed [34]. We used the visual association test (VAT), total immediate recall, and the Dutch version of the Rey Auditory Verbal Learning test (delayed recall) to assess memory. Language was assessed by VAT naming and category fluency (animals). The Trail-Making Test (TMT) part A, Digit Span forwards, and the Stroop test I and II were used for attention. Executive functioning was assessed by TMT B, Digit Span backwards, Stroop test III, the Frontal Assessment Battery, and the Dutch version of the Controlled Oral Word Association Test (letter fluency). Finally, we assessed visuospatial functioning by Visual Object and Space Perception battery: tests incomplete letters, dot counting, and number location.

For every test, we derived $z$-scores using the mean and standard deviation values from a group of healthy controls $(n=360)$ [34]. TMT A, TMT B, and Stroop Test scores were log-transformed to account for the nonnormal distribution of the data and multiplied by -1 so that lower scores would indicate worse performance. In case TMT B was aborted and TMT A was available $(n=$ 132), we estimated the TMT B score using the multiplication of TMT A score with mean TMT B/A score ratio from the respective diagnostic group [35]. Thereafter, based on available tests, we used $z$-scores to compile a composite score for each of the five cognitive domains.

\section{CSF}

CSF was obtained by lumbar puncture between L3/4, L4/5, or L5/S1 intervertebral space, using a 25-gauge needle and a syringe [36]. The samples were collected in polypropylene microtubes and centrifuged at $1800 \mathrm{~g}$ for $10 \mathrm{~min}$ at $4{ }^{\circ} \mathrm{C}$. Thereafter, the samples were frozen at $20^{\circ} \mathrm{C}$ until manual analyses of $\mathrm{Ab}_{42}$, tau, and p-tau were performed using sandwich ELISAs [Innotest assays: $\beta$ amyloid1-42, tTAU-Ag, and PhosphoTAU-181p; Fujirebio (formerly Innogenetics)] at the Neurochemistry Laboratory of the Department of Clinical Chemistry of 
VUmc. As the median CSF $A \beta_{42}$ values of our cohort have been gradually increasing over the years [37], we determined CSF amyloid- $\beta$ status using $A \beta_{42}$ values that had been adjusted for the longitudinal upward drift. We used a uniform cut-off of $813 \mathrm{pg} / \mathrm{mL}$ to dichotomize CSF data [38].

\section{PET}

Amyloid- $\beta$ PET scanning is not part of standard diagnostic process in the Amsterdam Dementia Cohort. Patients underwent an amyloid- $\beta$ PET for research purposes in the vast majority [39-44] or otherwise in case of a diagnostic dilemma. Amyloid- $\beta$ PET scans were performed using the following PET scanners: ECAT EXACT HR+ scanner (Siemens Healthcare, Germany) and Gemini TF PET/CT, Ingenuity TF PET-CT and Ingenuity PET/MRI (Philips Medical Systems, the Netherlands). We included PET scans using four different radiotracers: $\left[{ }^{18} \mathrm{~F}\right]$ Florbetaben $[39,44](n=322,42 \%)$, $\left[{ }^{11} \mathrm{C}\right]$ PIB [41-43] $(n=271,35 \%),\left[{ }^{18} \mathrm{~F}\right]$ Flutemetamol [45] $(n=151,20 \%)$, and $\left[{ }^{18} \mathrm{~F}\right]$ Florbetapir [40] $(n=24,3 \%)$. PET scans were rated as positive or negative based on visual read by an expert nuclear medicine physician $(\mathrm{BvB})$. PET scans were performed, on average, within 54 $( \pm 75)$ days of the lumbar puncture.

\section{MRI}

The acquisition of MRI scans has been extensively described previously [24]. During the period of 2005 to 2017, the following scanners have been used: Discovery MR750 and Signa HDXT (both GE Medical Systems, USA), Ingenuity TF PET/MR (Philips Medical Systems, The Netherlands), Titan (Toshiba Medical Systems, Japan), and Magnetom Impact and Sonata (Siemens Healthcare, Germany). The MRI protocol included 3D T1-weighted, T2-weighted, fluid-attenuated inversion recovery (FLAIR), gradientecho T2*, and/or susceptibility-weighted imaging sequences. The scans were visually assessed by a neuroradiologist on three different image planes. Parietal atrophy was rated using the posterior cortical atrophy (PCA) scale [46], medial temporal atrophy using the medial temporal lobe atrophy (MTA) scale [47], and the extent of white matter hyperintensities according to the Fazekas scale [48]. MTA and PCA scores were scored separately for right and left and averaged thereafter. In addition, the scans were assessed for the existence of lacunes and microbleeds.

\section{Patient groups}

We stratified the patients based on syndrome diagnosis: subjective cognitive decline (SCD, $n=194(29 \%)$ ) [49], mild cognitive impairment (MCI, $n=127(17 \%)$ ), and dementia $(n=447(58 \%))$. Within the dementia group, 309
(69\%) patients had the diagnosis of Alzheimer's disease, $66(15 \%)$ a diagnosis within the frontotemporal dementia spectrum, 22 (5\%) dementia with Lewy bodies, 6 (1\%) vascular dementia, and $44(10 \%)$ other dementia syndromes. Patient diagnosis was determined without knowledge of PET or CSF status. To reflect the information provided to the models in our analysis, we present patient group characteristics based on the binarized amyloid- $\beta$ status on PET and CSF: concordantly positive $(\mathrm{PET}+/ \mathrm{CSF}+)$ or negative (PET-/CSF - for amyloid- $\beta$ pathology, or discordantly positive amyloid- $\beta$ status based on PET (PET+/CSF-) or CSF (PET/CSF+).

\section{Statistical analysis}

Statistical analysis was performed using $\mathrm{R}$ software (version 3.4.4) [50]. When presenting our study population by binarized PET/CSF status groups, we compared patient features using chi-squared tests, two samples $t$ tests, Wilcoxon rank-sum tests, and linear regression models with Bonferroni correction for group-wise testing. Cognitive scores were compared while adjusting for age, sex, education, and syndrome diagnosis.

All subsequent analyses were performed in the total patient group as well as in the syndrome diagnosis groups of $\mathrm{SCD}, \mathrm{MCI}$, and dementia. We first summarized the relative predictive power of every variable in predicting PET and CSF amyloid- $\beta$ status using random forest modeling. We performed random forest modeling to (i) get an estimate of the predictive power of variables in a setting, where all variables are present in the model; (ii) compare the importance of variables between models predicting PET and CSF amyloid- $\beta$ status; and (iii) select patient features for multivariable logistic regression models. As classifier models are affected by missing data, we accounted for missing values using multiple imputations (using the mice library [51] including only the 17 predictor variables later used for analysis; with 25 imputations and 5 iterations) (Additional file 1: Table S1). For each of the imputed dataset, we ran two conditional random forest models (ntree = 1001$, mtry $=5)[52,53]$, predicting separately PET and CSF status using various patient features associated with Alzheimer's disease [18-20]. As predictors, we selected demographic information (age, sex, education), biomarkers (APOE \&4 positivity, CSF tau, and $\mathrm{p}$-tau), cognitive measures (MMSE; $z$-scores for memory, language, attention, executive, visuospatial), and MRI scores (MTA, PCA, Fazekas scale, the presence of lacunes and microbleeds). Accuracy, sensitivity, and specificity of the random forest models were evaluated using the mean out-of-bag (OOB) error estimates. Using this method, the performance of every tree in the random forest model is evaluated on the approximately $37 \%$ of observations that are not used for its training, allowing a means to train the model and perform analysis in the same dataset [54]. 
We used the area-under-the-curve (AUC)-based permutation variable importance measure (VIM) to estimate the relative predictive power for every patient feature. This measure was selected because of its higher accuracy in datasets with an unbalanced outcome class [55] and we expected this to be especially helpful in the SCD group with a low prevalence of amyloid- $\beta$ positivity. The AUC-based permutation variable VIM is calculated as follows:

$$
\mathrm{VI}_{j}^{(\mathrm{AUC})}=\frac{1}{\text { ntree }} \sum_{t=1}^{\text {ntree }}\left(\mathrm{AUC}_{t j}-\mathrm{AUC}_{t j}^{\sim}\right)
$$

where (1) ntree denotes the number of trees in the forest whose $\mathrm{OOB}$ observations include observations from both outcome classes, (2) $\mathrm{AUC}_{t j}$ denotes the area under the curve computed in the $\mathrm{OOB}$ observations in the selected tree before permuting predictor $j$, and (3) $\mathrm{AUC}_{t j}^{\sim}$ denotes the area under the curve computed from the OOB observations in tree $t$ after randomly permuting predictor $j$ [55]. As the variable is indirectly dependent on the size of population, these variables cannot be reliably compared between populations of different size. We preferred this VIM measure over several alternative VIM measures, including the Gini impurity criterion (which might show bias when predictors vary in their number of categories or scale of measurement), the error-ratebased permutation mutation (which might falsely identify the importance of highly correlated variables), or error-rate-based conditional permutation (which performs best in balanced datasets, while our dataset is unbalanced) $[53,55,56]$.

For the second stage of the analysis, we selected patient features based on their predictive value in the random forest models. Similar to a previous study [20], we included patient features when their median VIM over the 25 random forests models for predicting either PET or CSF was higher than the median VIM of all the features for the patient group. Firstly, using Wilcoxon signed-rank tests for paired data in 1000x bootstrapped samples with replacement, we compared the VIM of every selected patient feature between the parallel random forest models predicting amyloid- $\beta$ PET and CSF status. Secondly, to determine the unadjusted predictive power of these patient features, we performed bivariate logistic regression models with either PET or CSF positivity as the outcome and the selected patient features as predictors. Thirdly, to investigate the added predictive value of a patient feature to the other amyloid- $\beta$ modality, we performed multivariable logistic regression models, with either PET or CSF positivity as the outcome and the selected patient feature with the status of the other amyloid- $\beta$ modality as predictors. For these models, we assumed that if PET and CSF would truly provide equal information about amyloid status, additional patient features should never be significant predictors in these models, as the other amyloid status would already provide sufficient predictive power. However, if a patient feature added significant information, this would show a stronger association between the feature and the predicted amyloid- $\beta$ modality.

Finally, as confirmation for our main findings for $A P O E \& 4$ positivity, CSF tau, and p-tau, we compared these multivariable logistic regression models to a univariate logistic regression model, where PET or CSF status was predicted only by the status of the other amyloid modality. We calculated the difference in Akaike Information Criterion (AIC) between the two models to investigate the change in model fit. A decrease in AIC between models can be interpreted as some (0-2), considerable (4-7), or strong $(>10)$ evidence for gain in model fit in favor of the second model [57].

We calculated the odds ratios (OR) with corresponding 95\% confidence intervals for every patient feature both in the original dataset and in the $25 \times$ imputed datasets. Non-overlapping confidence intervals were considered significantly different. We used the false discovery rate (FDR) correction with a significance level of 0.05 to account for multiple testing [58].

\section{Results}

\section{PET/CSF discordance}

In total, 32 patients $(4 \%)$ were discordantly amyloid- $\beta$ positive based on PET and 65 (8\%) based on CSF. The proportion of PET/CSF discordance was $15 \%$ in SCD $(n=30), 13 \%$ in MCI $(n=17)$, and $11 \%$ in dementia $(n=$ $50)$. Of the discordant group, $67 \%(n=20 / 30)$ of SCD, $53 \%(n=9 / 17)$ of MCI, and $72 \%(n=36 / 50)$ of dementia were PET-CSF+.

\section{Overview of features}

Patient characteristics grouped by PET/CSF status are summarized in Table 1 and CSF $A \beta_{42}$ levels shown in Fig. 1. In general, the PET $+\mathrm{CSF}+$ group showed a higher proportion of APOE $\varepsilon 4$ carriers, more AD-like CSF markers, MRI features, and lower cognitive scores compared to PET-CSF- group. CSF tau and p-tau were lower in both PET-CSF- and PET-CSF+ groups, compared to $\mathrm{PET}+\mathrm{CSF}-$ and $\mathrm{PET}+\mathrm{CSF}+$. The $\mathrm{PET}-\mathrm{CSF}-$ group contained a lower proportion of $A P O E \varepsilon 4$ carriers and better cognitive scores than patients in the discordant groups.

\section{Patient feature selection}

Out-of-bag accuracy, sensitivity, and specificity rates for the random forest models are reported in Additional file 1: Table S2. 
Table 1 Patient groups by PET/CSF amyloid status

\begin{tabular}{|c|c|c|c|c|}
\hline & PET-CSF- & PET+CSF- & PET-CSF+ & PET+CSF+ \\
\hline \multicolumn{5}{|l|}{ Demographics } \\
\hline$N(\%)$ & $315(41)$ & $32(4)$ & $65(8)$ & $356(46)$ \\
\hline Sex, male (\%) & $211(67)^{\mathrm{D}}$ & $17(53)$ & $41(63)$ & $192(54)^{\mathrm{A}}$ \\
\hline Age, years (mean (SD)) & $62.8(7.7)$ & $65.0(7.7)$ & $62.4(9.0)$ & $63.7(7.3)$ \\
\hline Education (median [IQR]) & $5[4,6]$ & $5[4,6]$ & $5[4,6]$ & $5[4,6]$ \\
\hline \multicolumn{5}{|l|}{ Syndrome diagnosis (\%) } \\
\hline SCD & $136(43)$ & $10(31)$ & $20(31)$ & $28(8)$ \\
\hline $\mathrm{MCl}$ & $55(18)$ & $8(25)$ & $9(14)$ & $55(15)$ \\
\hline AD dementia & $28(9)$ & $11(34)$ & $17(26)$ & $253(71)$ \\
\hline Non-AD dementia & $96(31)$ & $3(9)$ & $19(29)$ & $20(6)$ \\
\hline \multicolumn{5}{|l|}{ Biomarkers } \\
\hline CSF-PET difference, days (mean (SD)) & $61(75)$ & $54(70)$ & $74(84)$ & $58(67)$ \\
\hline CSF A $\beta_{42}, \mathrm{pg} / \mathrm{mL}$ (median [IQR]) & $1134[989,1275]^{\mathrm{BCD}}$ & $875[832,959]^{\mathrm{ACD}}$ & $674[625,741]^{\mathrm{ABD}}$ & $615[537,688]^{\mathrm{ABC}}$ \\
\hline CSF tau, pg/mL (median [IQR]) & $277[207,375]^{\mathrm{BD}}$ & $468[324,716]^{\mathrm{AC}}$ & $287[174,501]^{\mathrm{BD}}$ & $609[403,845]^{A C}$ \\
\hline CSF p-tau, pg/mL (median [IQR]) & $44[35,54]^{\mathrm{BD}}$ & $67[50,90]^{A C}$ & $41[28,61]^{B D}$ & $82[58,103]^{A C}$ \\
\hline APOE E4 positivity (\%) & $84(28)^{B C D}$ & $18(60)^{\mathrm{A}}$ & $32(52)^{A}$ & $238(70)^{\mathrm{A}}$ \\
\hline \multicolumn{5}{|l|}{ Cognition } \\
\hline MMSE (mean (SD)) & $26(3)^{B D}$ & $24(5)^{\mathrm{A}}$ & $25(4)$ & $23(4)^{\mathrm{A}}$ \\
\hline Memory z-score (mean (SD)) & $-1.39(2.27)^{\mathrm{BD}}$ & $-3.14(2.73)^{\mathrm{A}}$ & $-2.20(2.96)$ & $-3.34(2.76)^{\mathrm{A}}$ \\
\hline Language $z$-score (mean (SD)) & $-0.65(1.29)$ & $-0.95(1.48)$ & $-1.44(2.27)^{C}$ & $-1.03(1.83)^{\mathrm{D}}$ \\
\hline Attention z-score (mean (SD)) & $-0.69(1.09)^{\mathrm{D}}$ & $-0.82(1.08)$ & $-0.98(1.02)$ & $-1.10(1.21)^{\mathrm{A}}$ \\
\hline Executive $z$-score (mean (SD)) & $-1.01(1.38)^{\mathrm{D}}$ & $-1.39(1.55)$ & $-1.27(1.32)$ & $-1.53(1.40)^{\mathrm{A}}$ \\
\hline Visuospatial z-score (mean (SD)) & $-0.34(1.18)^{\mathrm{D}}$ & $-1.04(1.90)$ & $-0.90(1.70)$ & $-1.36(2.40)^{\mathrm{A}}$ \\
\hline \multicolumn{5}{|l|}{ MRI } \\
\hline MRI-amyloid difference, days (mean (SD)) & $16(50)^{C}$ & $35(60)$ & $44(78)^{\mathrm{AD}}$ & $14(45)^{C}$ \\
\hline MTA (median [IQR]) & $0.5[0.0,1.0]^{\mathrm{D}}$ & $0.5[0.0,1.0]$ & $0.5[0.0,1.8]$ & $1.0[0.5,1.5]^{\mathrm{A}}$ \\
\hline PCA (median [IQR]) & $1.0[0.0,1.1]^{\mathrm{D}}$ & $1.0[1.0,1.0]$ & $1.0[0.0,1.4]^{\mathrm{D}}$ & $1.0[1.0,2.0]^{\mathrm{AC}}$ \\
\hline Fazekas (median [IQR]) & $1.0[0.0,1.0]$ & $1.0[0.8,1.0]$ & $1.0[0.0,2.0]$ & $1.0[0.0,1.0]$ \\
\hline Lacune positivity (\%) & $14(6)$ & $0(0)$ & $7(11)$ & $17(7)$ \\
\hline Microbleed positivity (\%) & $31(13)$ & $4(15)$ & $4(7)$ & $54(21)$ \\
\hline
\end{tabular}

Education is staged by Verhage classification (1-7). Lacune and microbleed positivity is scored, if at least one is present. MTA medial temporal lobe atrophy scale, $P C A$ posterior cortical atrophy scale

$A, B, C$, and D indicate a significant difference $(p<0.05)$ from other groups:

A-difference from PET-CSF-

$\mathrm{B}$ - difference from PET+CSF-

C-difference from PET-CSF+

$\mathrm{D}$-difference from PET+CSF+

VIM values over the 25 random forest models (one with each set of imputed data) for the total group are shown in Fig. 2a. APOE $\varepsilon 4$ positivity was the most important predictor for amyloid- $\beta$ positivity in the total patient group for both PET and CSF. CSF tau was similarly important when predicting PET or CSF, but CSF p-tau was a more important predictor for PET compared to CSF. Subsequently, we stratified for syndrome diagnosis (Fig. 2b-d). In SCD, APOE \&4 positivity was a stronger predictor for CSF than PET, whereas CSF p-tau was more associated with PET than CSF amyloid- $\beta$ status.
Additionally, MMSE and memory score had a stronger association with CSF than PET. CSF tau was equally important for predicting PET or CSF amyloid- $\beta$ status. In contrast to the findings in $\mathrm{SCD}$, in MCI, $\mathrm{APOE} \varepsilon 4 \mathrm{car}$ riership was a stronger predictor for PET than for CSF. Moreover, CSF tau and p-tau were more important for predicting PET than for CSF amyloid- $\beta$ status. In dementia, CSF p-tau was more predictive of PET than CSF, but CSF tau was a stronger predictor for CSF than for PET amyloid- $\beta$ status. Both PET and CSF had a strong association to $A P O E \& 4$ carriership. Finally, 


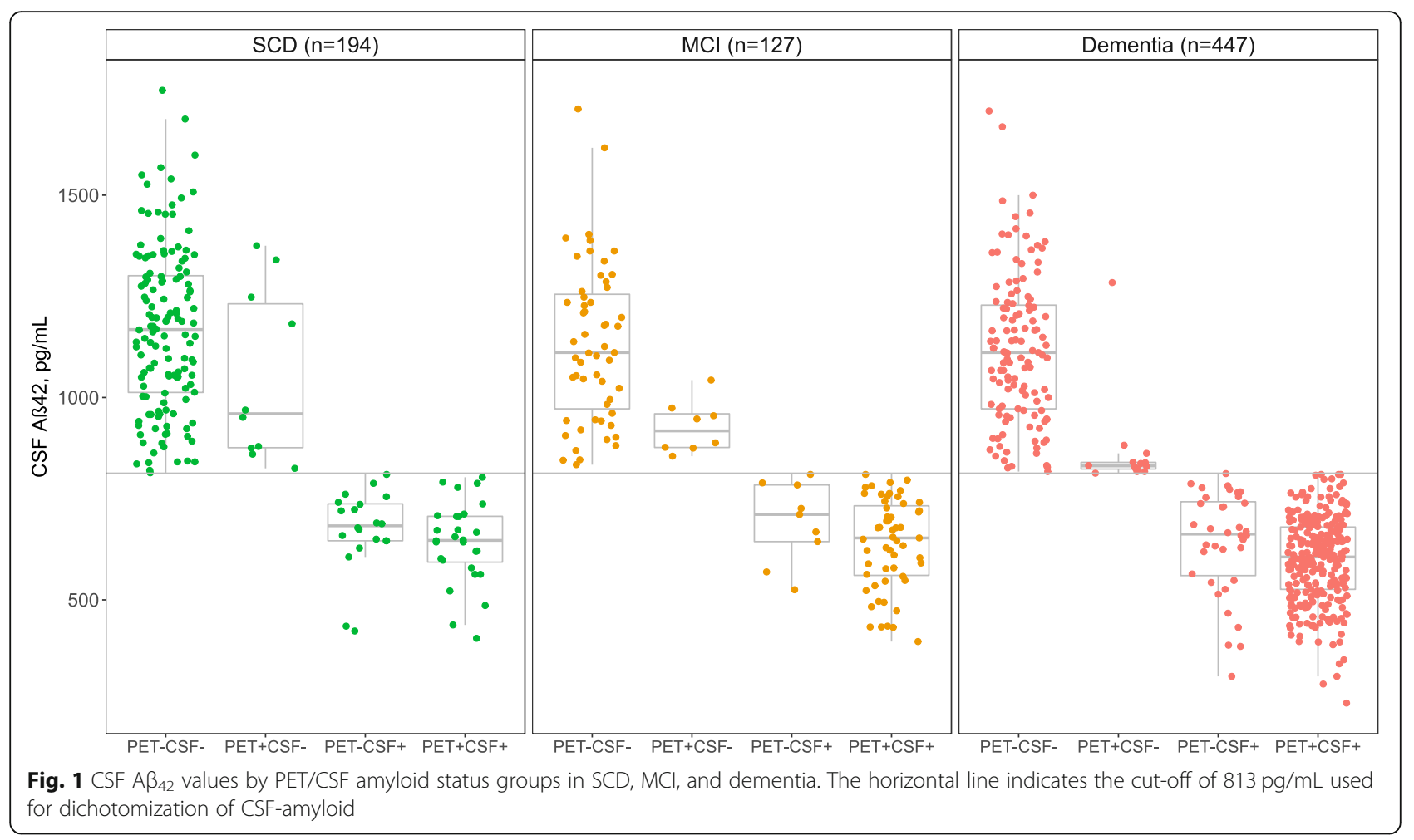

visuospatial and memory scores were more important for predicting PET positivity.

Additionally, in a subanalysis in the total patient group excluding patients with concordantly negative amyloid status and MCI/dementia, CSF p-tau was the most important predictor for PET but not for CSF $(n=589$, Additional file 1: Figure S1).

\section{Univariate logistic regression models}

We verified the predictive ability of the selected patient features with bivariate logistic regression models for PET and CSF status (Table 2; all possible models in Additional file 1: Table S3). The bivariate models largely confirmed the feature selection of the random forest procedure, as $A P O E$ \&4, CSF tau, and CSF p-tau were consistently significant predictors in all groups. In the total group and dementia, most of the patient features selected based on the random forest models were significant predictors.

Amyloid-adjusted multivariable logistic regression models We investigated the added predictive value of the selected patient features to the other amyloid- $\beta$ modality with multivariable logistic regression models (odds ratios and $p$ values are shown in Table 3; all possible models in Additional file 1: Table S4). In the total group, increased levels of CSF p-tau and were more strongly associated with PET than CSF. In SCD, increased levels of CSF ptau and tau were predictive of only PET, but not CSF positivity. APOE $\varepsilon 4$ carriership and lower MMSE scores showed a predictive trend towards amyloid- $\beta$ status based on CSF, but not on PET. In MCI, a positive PET scan was more strongly predicted by $A P O E \varepsilon 4$ and by increased levels of CSF p-tau and tau. Finally, in dementia, PET status had a stronger association with increased levels of CSF p-tau and tau and with a worse performance in memory and visuospatial ability than CSF amyloid- $\beta$ status. $A P O E \& 4$ carriership was similarly associated with both PET and CSF. No patient feature showed a higher association with CSF in dementia.

\section{AIC change between multivariable and univariate models including amyloid status only}

Multivariable logistic regression models including APOE $\varepsilon 4$ carriership, CSF tau, and CSF p-tau as predictors usually showed significant $(>2)$ decrease of AIC compared to univariate logistic regression models, where PET or CSF status was predicted only by the status of the other amyloid modality (Table 4). Overall, differences between change of AIC when predicting PET or CSF were similar to findings from previous random forest and multivariate logistic regression models, indicating consistent results across multiple statistical approaches.

\section{Discussion}

We investigated the predictive patterns of various patient features for amyloid- $\beta$ status based on PET or CSF to determine (i) whether these features have a different 


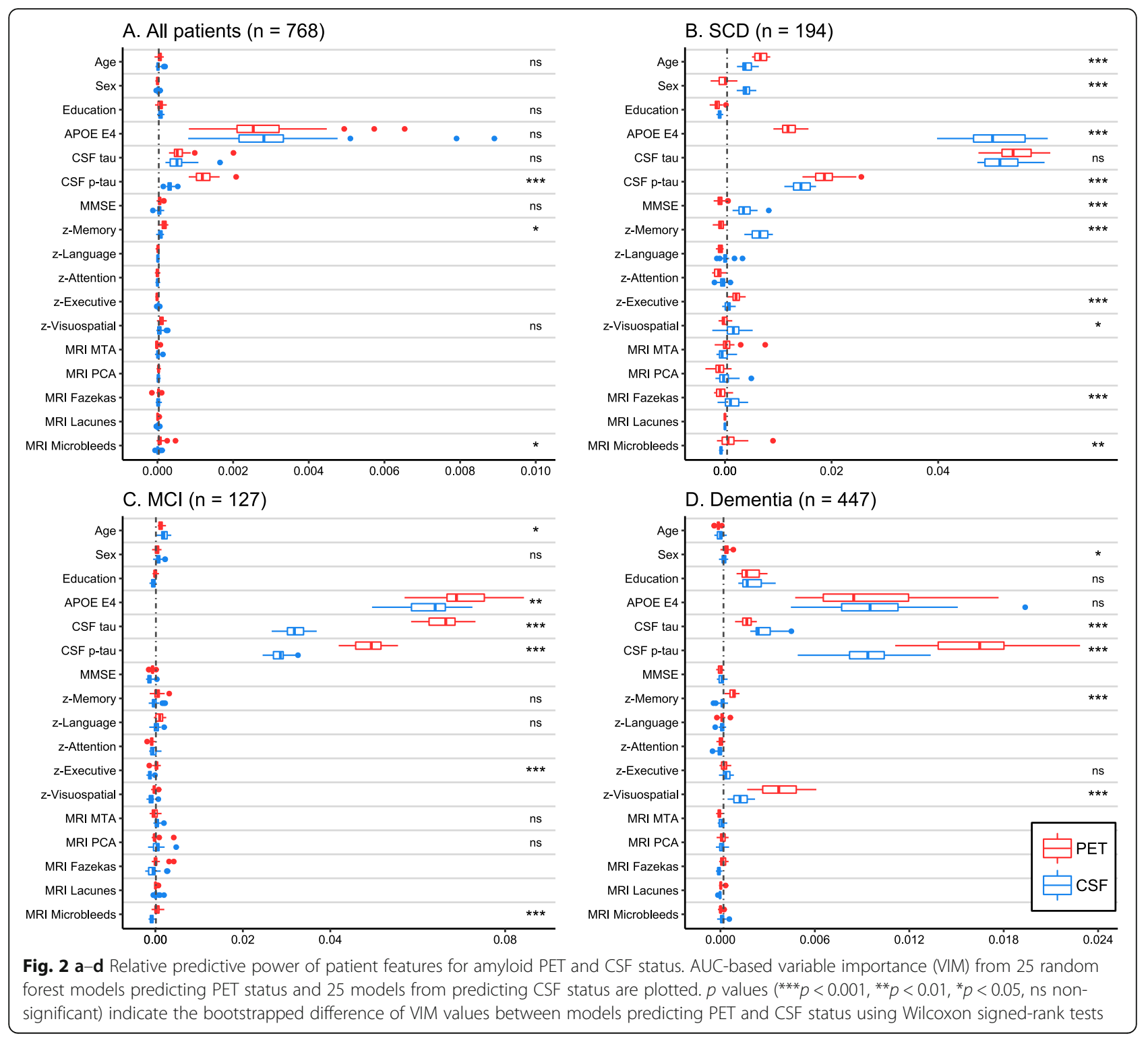

association with PET or CSF and (ii) whether this differs per disease stage. We found significant differences in the predictive strength of patient features for amyloid- $\beta$ status based on PET or CSF. For example, CSF tau and especially CSF p-tau consistently showed a stronger association with amyloid- $\beta$ status on PET. Additionally, the differential predictive pattern was influenced by the extent of cognitive impairment, as CSF tau was more important in SCD and MCI, while CSF p-tau became more important in the stage of dementia. Moreover, $A P O E \& 4$ carriership was more predictive towards CSF status in SCD, whereas it was more predictive towards PET in MCI. These findings suggest that PET and CSF do not provide identical information about the stage of Alzheimer's disease.

The idea to study differences in the predictive strength of patient features for PET/CSF amyloid- $\beta$ status was based on the differences in characteristics of patients with discordant amyloid- $\beta$ biomarkers, which have been theorized to be caused by various factors. Possible explanations for the discordance include individual variances in CSF $A \beta_{42}$ production [59], the composition of amyloid- $\beta$ plaques [60], differences in the structure of $A \beta$ fibrils [61], or a variety of technical issues [62, 63], including the variability in cut-off values for CSF $A \beta_{42}$ [14]. It has also been proposed that in the earliest stages of amyloid- $\beta$ accumulation CSF $A \beta_{42}$ analysis might be more sensitive, as the decrease in the concentration of soluble isoforms might precede fibrillar amyloid- $\beta$ plaque deposition detectable by PET [22]. Overall, we found significant differences in the relation between amyloid PET and CSF status and other biological variables, such as APOE genotype and (p)tau concentrations. 


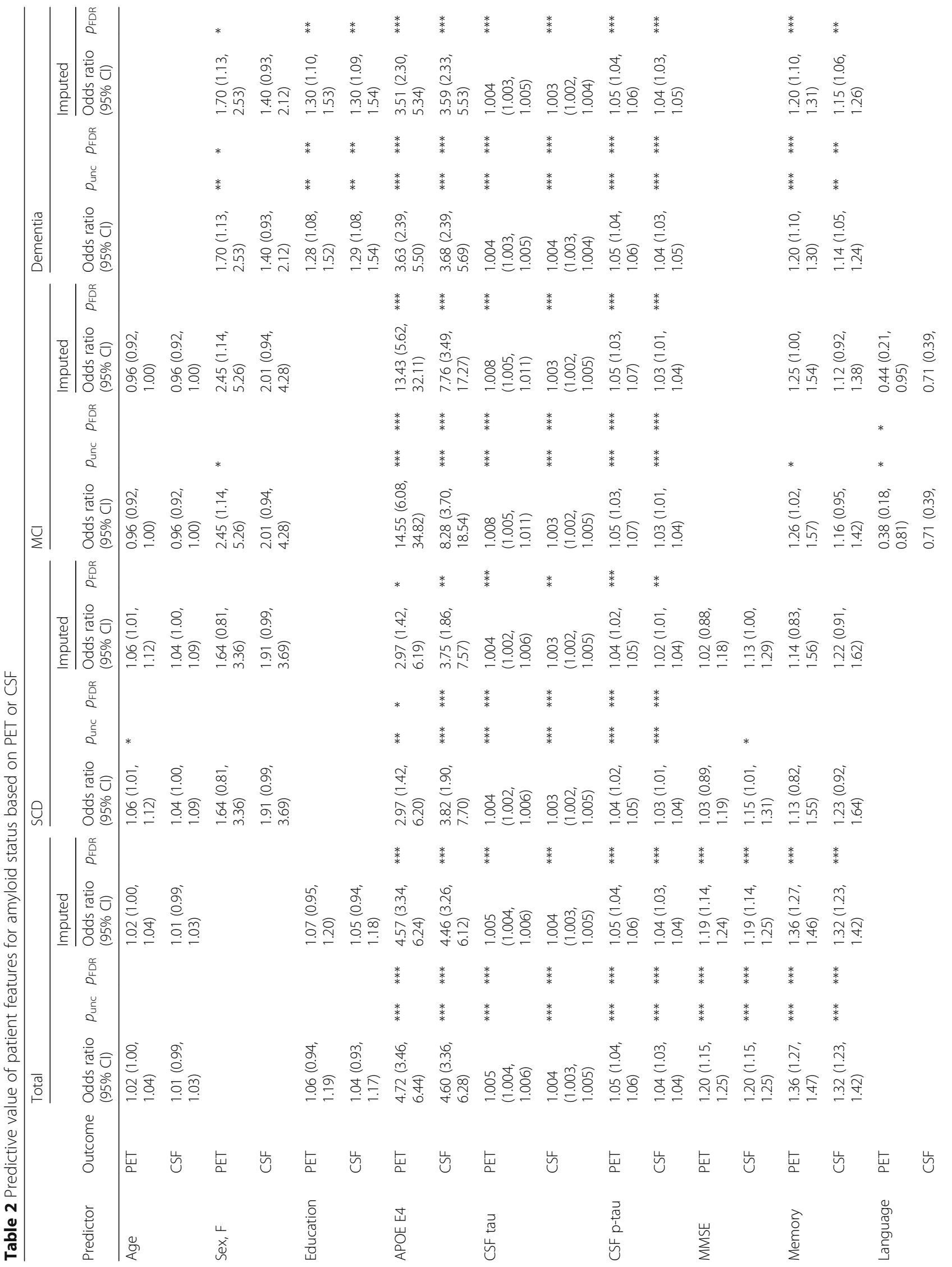




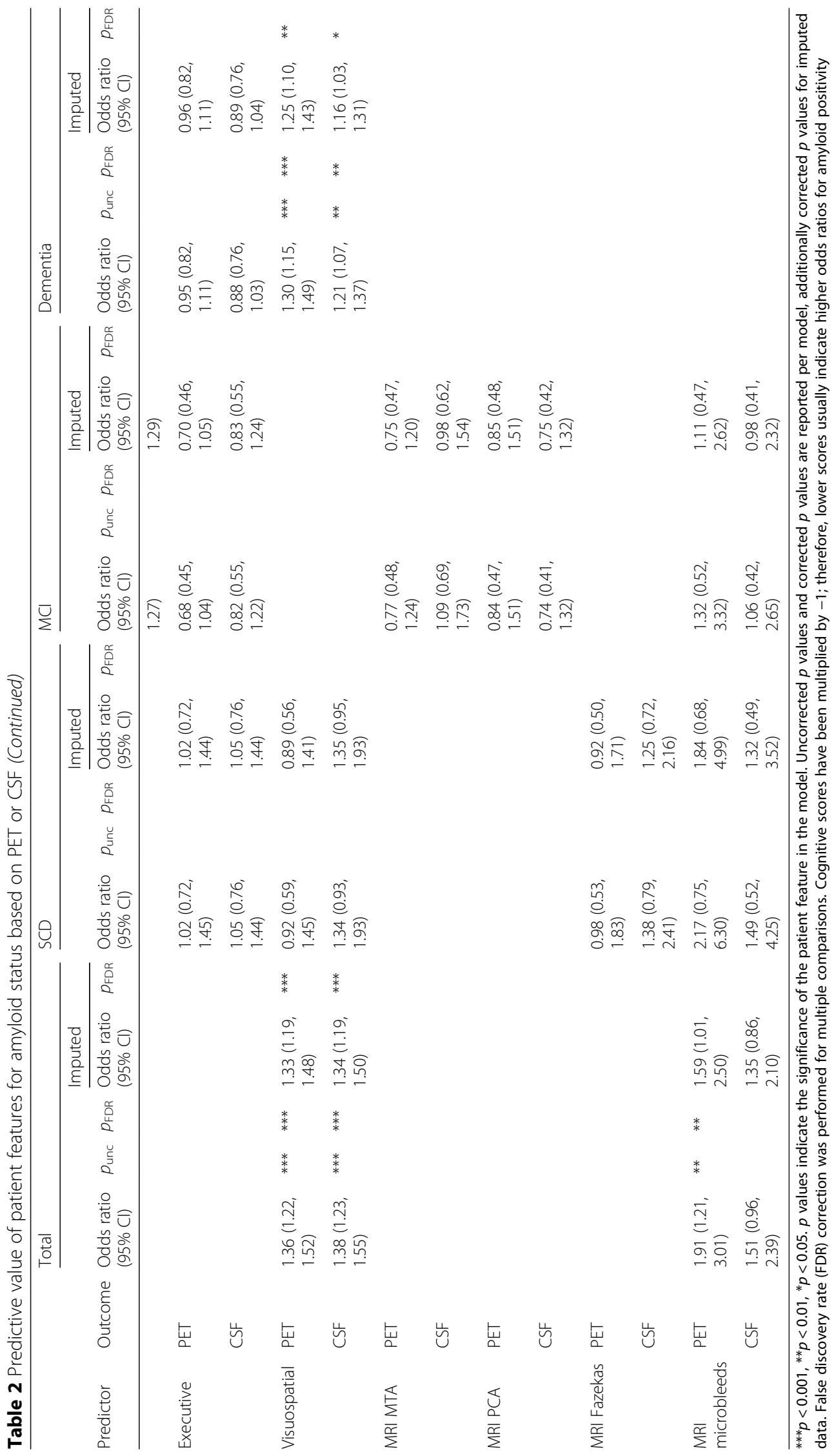




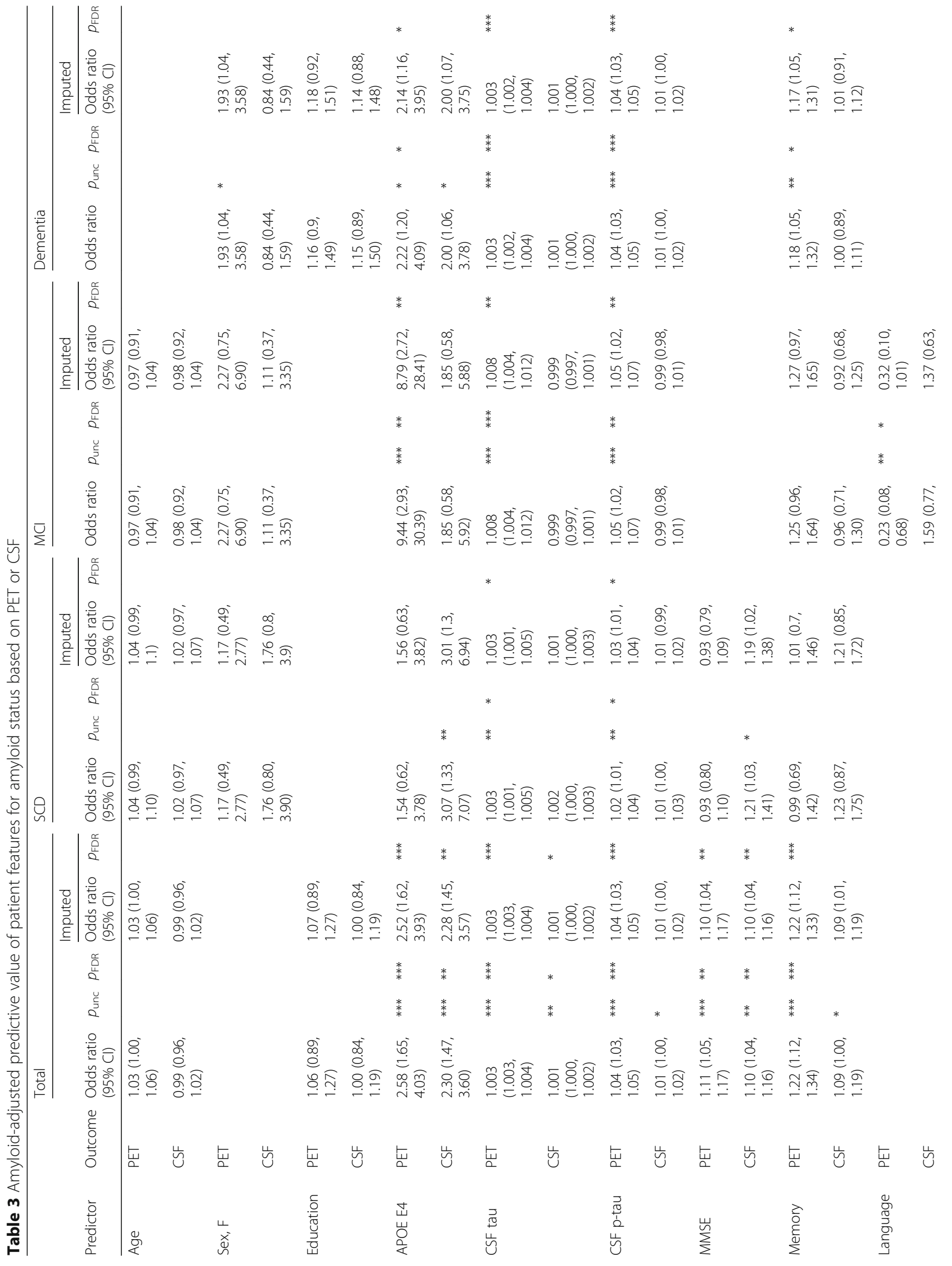




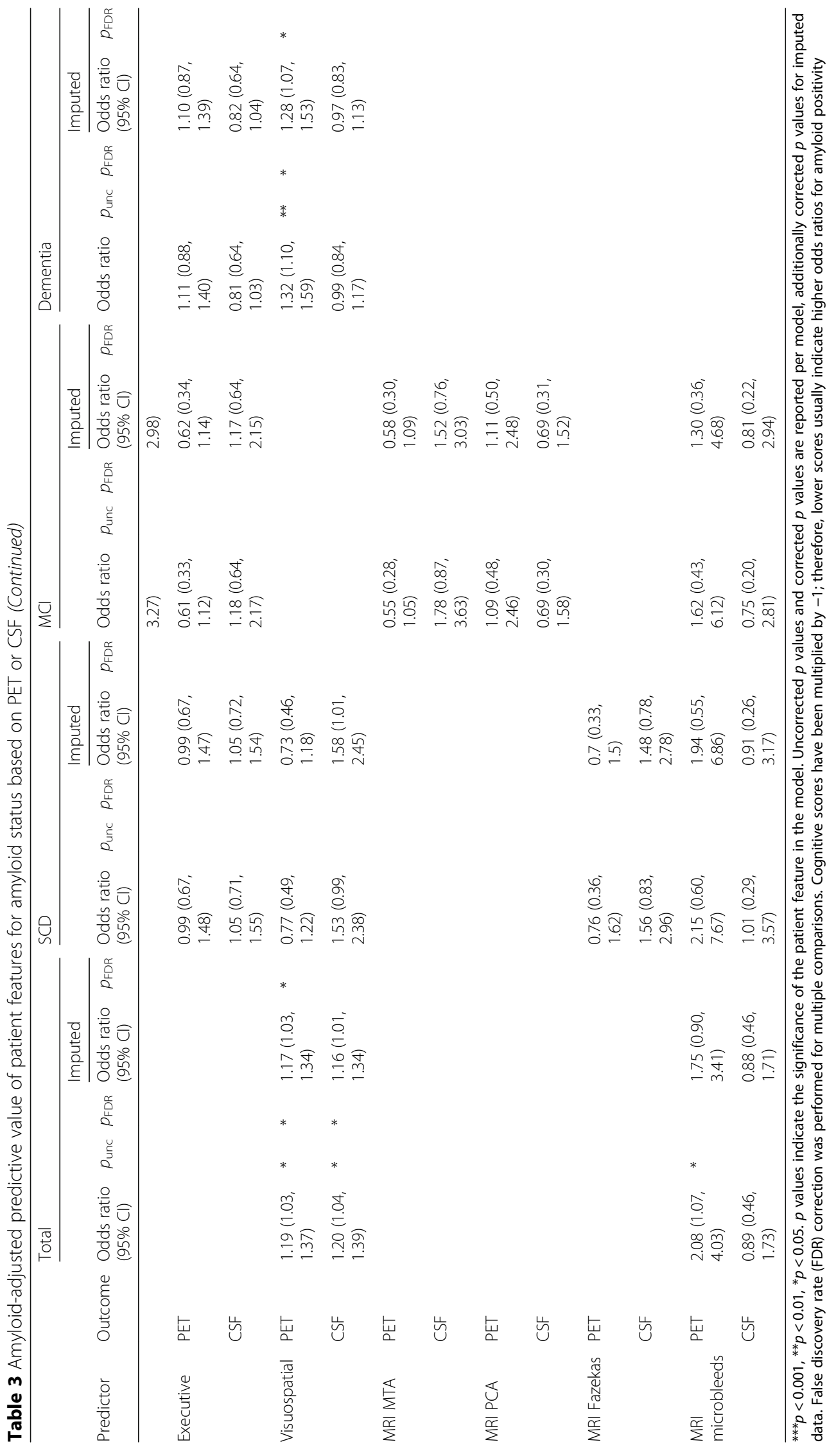


Table 4 Information gain of multivariable logistic regression models compared to univariate logistic regression including only amyloid modalities

\begin{tabular}{|c|c|c|c|c|c|c|c|}
\hline & & AIC & & & $\mathrm{AIC}$ & & \\
\hline & Predictor & $\begin{array}{l}\mathrm{PET} \sim \\
\mathrm{CSF}\end{array}$ & $\begin{array}{l}\mathrm{PET} \sim \\
\mathrm{CSF}+\text { predictor }\end{array}$ & AIC difference & $\begin{array}{l}\text { CSF } \sim \\
\text { PET }\end{array}$ & $\begin{array}{l}\text { CSF } \sim \\
\text { PET + predictor }\end{array}$ & AIC difference \\
\hline Total & APOE E4 positivity & 580 & 533 & 47 & 573 & 531 & 42 \\
\hline & CSF tau & 580 & 508 & 71 & 573 & 563 & 10 \\
\hline & CSF p-tau & 580 & 481 & 99 & 573 & 555 & 17 \\
\hline SCD & APOE E4 positivity & 142 & 138 & 4 & 167 & 152 & 15 \\
\hline & CSF tau & 142 & 132 & 10 & 167 & 162 & 5 \\
\hline & CSF p-tau & 142 & 132 & 10 & 167 & 163 & 4 \\
\hline $\mathrm{MCl}$ & APOE E4 positivity & 104 & 86 & 18 & 104 & 100 & 4 \\
\hline & CSF tau & 104 & 74 & 30 & 104 & 105 & -1 \\
\hline & CSF p-tau & 104 & 83 & 21 & 104 & 106 & -2 \\
\hline Dementia & APOE E4 positivity & 317 & 295 & 22 & 286 & 267 & 19 \\
\hline & CSF tau & 317 & 294 & 23 & 286 & 285 & 2 \\
\hline & CSF p-tau & 317 & 263 & 54 & 286 & 276 & 10 \\
\hline
\end{tabular}

This table illustrates the change in Akaike Information Criterion (AIC) from the bivariate models including only amyloid modalities (PET $\sim$ CSF and CSF $\sim$ PET) to multivariable models including also an additional predictor. AIC measures model fit and penalizes adding additional predictors. A decrease in AIC between models shows some (0-2), considerable (4-7), or strong (>10) evidence for gain in model fit for the second model

The existence of differing predictive patterns between the two modalities implies that PET/CSF discordance may not only be explained by technical variation, but reflect differences in biological substrate between the modalities. In our previous work, we already showed that PET/CSF discordance has potential clinical consequences [16]. These results could also have an effect for future practice in $\mathrm{AD}$ research as well as patient care, as the two modalities are currently used as equal alternatives $[2,11]$.

Our main finding was that CSF p-tau and tau had a stronger association to amyloid- $\beta$ based on PET compared to CSF. If we assume that CSF is a more sensitive modality for amyloid- $\beta$ pathology, then the weaker association with tau could be explained by CSF $A \beta_{42}$ capturing an earlier stage amyloid- $\beta$ preceding tau pathology. This was reflected by the predictive patterns in the multivariable logistic regression models: when predicting PET status by CSF status, CSF (p)tau adds information about the added burden of disease (including advancing from $\mathrm{CSF}+\mathrm{PET}-$ to $\mathrm{CSF}+\mathrm{PET}+$ ). When predicting CSF amyloid- $\beta$ positivity, however, the existence of amyloid- $\beta$ pathology on PET already provides sufficient predictive power, of subjects already having reached a later stage in amyloid deposition. Overall, although the exact cause of this finding remains unclear, it supports the notion that PET detects more advanced stages of AD pathology, being in accordance with previous work by others [64]. Although CSF tau and p-tau have been shown to be highly correlated [65], the results of the random forest models imply that CSF tau is more predictive towards amyloid- $\beta$ pathology in SCD and MCI, whereas CSF p-tau is more predictive in dementia. This finding might be caused by wider neuronal death preceding the release of phosphorylated tau, although previous work seems to suggest that levels of CSF p-tau decrease in the later stages of $\mathrm{AD}$ [66-68]. Another possible explanation is that this finding is caused by the greater specificity of p-tau for $\mathrm{AD}$ pathology [69], as our cohort also included amyloidpositive patients diagnosed with non-AD dementia, likely due to secondary amyloid pathology.

Although we focus on the relative differences between PET and CSF, it should be emphasized that in the majority of cases these two modalities contain similar information. This was demonstrated by our finding that many of the selected patient features had similarly some predictive power for amyloid- $\beta$ pathology for both PET and CSF. Of them, the biological factors $A P O E \varepsilon 4$ carriership, CSF tau, and p-tau were most consistent in having significant predictive ability amyloid- $\beta$ status irrespective of the modality. These findings are not unexpected, as $A P O E$ \&4 carriership [18, 70, 71] and tau pathology $[2,72]$ are widely known to have a strong connection to amyloid- $\beta$ pathology in Alzheimer's disease. Cognitive measures and MRI visual reads showed overall a smaller predictive value towards amyloid- $\beta$ status, being in concordance with the theory that they show changes downstream of amyloid and tau pathology [73].

The main strength of our study is the large number of patients with both amyloid- $\beta$ modalities from a wellcharacterized cohort. Nevertheless, there were still a limited number of patients with discordant amyloid status, which could influence the reliability of our findings, especially when performing subgroup analysis. Another 


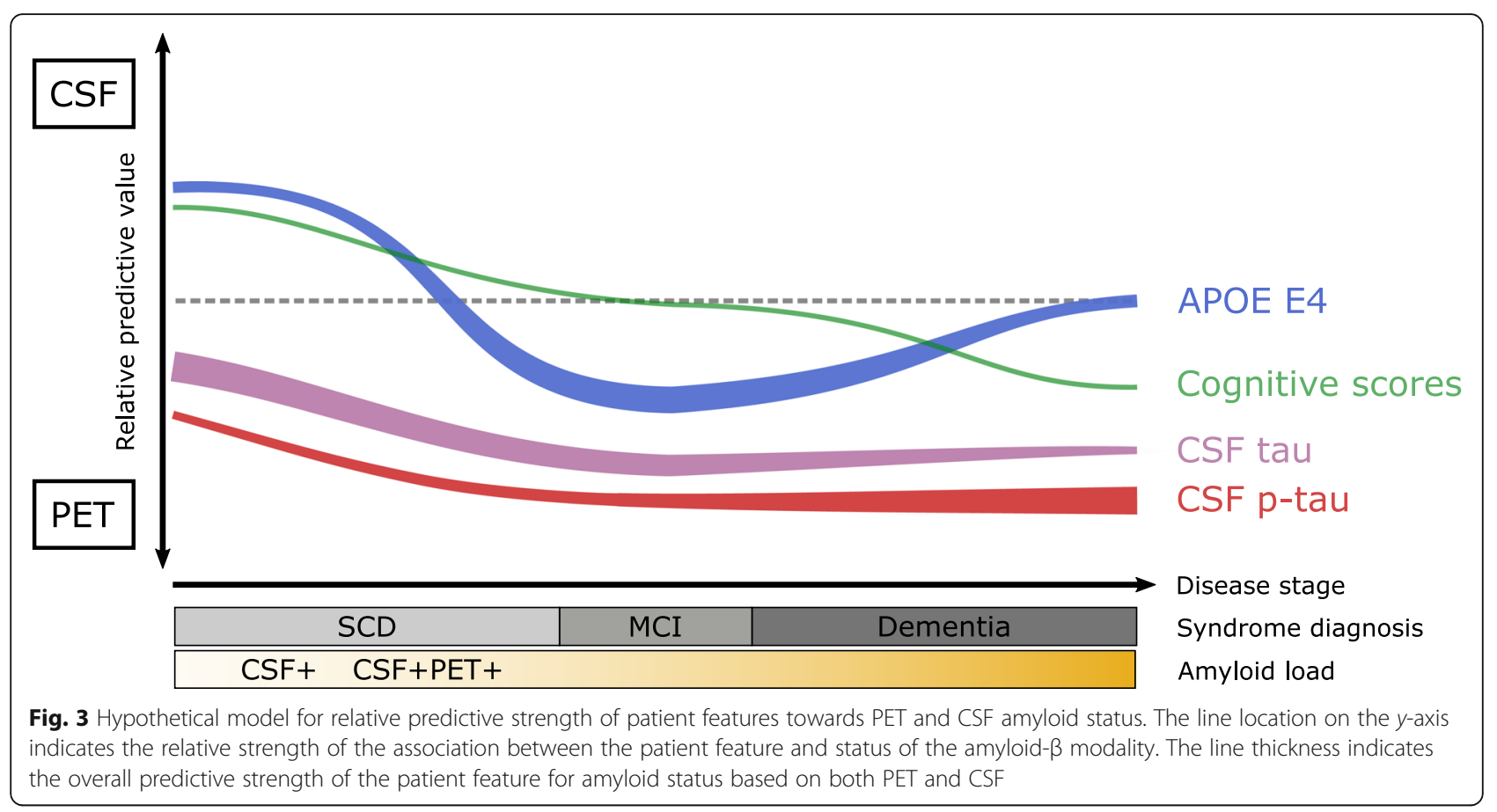

limitation is that due to the stratification by syndrome diagnoses, the outcome of amyloid- $\beta$ positivity was not equally prevalent. Our results in the multivariable logistic regression models might be influenced by the high concordance rate between PET and CSF status, although the results are supported by similar findings in the random forest models and by the decrease in AIC compared to models using only the other amyloid modality as predictors. Additionally, the included patients underwent amyloid- $\beta$ PET scans with four different radiotracers, allowing for variability in thresholds for amyloid- $\beta$ positivity. However, this effect is likely reduced by all of the PET scans being visually rated by the same experienced nuclear medicine physician. As continuous measures for PET imaging were not available, we dichotomized CSF $A \beta_{42}$ values, causing some loss of information, which could influence our results. Finally, this patient group did not have CSF $A \beta_{40}$ values available, which have been shown to correct for the individual variation in the production of amyloid- $\beta[74,75]$.

Our findings can be summarized by a hypothetical model highlighting the relative predictive power of patient features towards amyloid- $\beta$ status based on PET and CSF (Fig. 3). This model supports previous work, suggesting that CSF might be more sensitive in the early stages of amyloid- $\beta$ pathology, whereas PET status might be more specific to later stages of amyloid- $\beta$ accumulation. Although the modalities show similar information in the majority of cases, this could have implications for future research and clinical trials. For example, if aiming to capture the earliest stage of amyloid- $\beta$ pathology, CSF might be preferred over PET. On the contrary, if high confidence of significant amyloid- $\beta$ pathology is required, PET could be the modality of choice. Future work in other patient cohorts with a higher number of discordant PET/CSF cases is necessary to replicate these findings.

\section{Conclusion}

In this exploratory work, we demonstrated that although various patient features have general predictive value towards amyloid- $\beta$ status, there are finer differences revealed by discordant cases between the predictive pattern for amyloid- $\beta$ status based on PET and CSF. This indicates that PET-CSF discordance might include valuable information on underlying clinical and neuropathological differences.

\section{Supplementary information}

Supplementary information accompanies this paper at https://doi.org/10. 1186/s13195-019-0561-5.

Additional file 1: Table S1. Proportion of missing values per patient feature. Table S2. Out-of-bag accuracy, sensitivity and specificity for random forest models predicting amyloid PET and CSF status. Figure S1. Relative predictive power of patient features for amyloid PET and CSF status when removing PET-CSF- MCI and dementia patients. Table S3. Predictive value of patient features for amyloid status based on PET or CSF. Table S4. Amyloid-adjusted predictive value of patient features for amyloid status based on PET or CSF.

\section{Abbreviations}

AD: Alzheimer's disease; AIC: Akaike Information Criterion; AUC: Area under the curve; CSF: Cerebrospinal fluid; FDR: False discovery rate; MCl: Mild cognitive impairment; MMSE: Mini-Mental State Examination; MRI: Magnetic 
resonance imaging; MTA: Medial temporal lobe atrophy; OOB: Out-of-bag; OR: Odds ratios; PCA: Posterior cortical atrophy; PET: Positron emission tomography; SCD: Subjective cognitive decline; TMT: Trail-Making Test; UNC: Uncorrected; VAT: Visual association test; VIM: Variable importance measure

\section{Acknowledgements}

The Alzheimer Center Amsterdam is supported by Alzheimer Nederland and Stichting VUmc fonds. Research performed at the Alzheimer Center Amsterdam is part of the neurodegeneration research program of Amsterdam Neuroscience. The clinical database structure was developed with funding from Stichting Dioraphte. WvdfF was a recipient of ZonMWMemorabel ABIDE (project No 733050201), a project in the context of the Dutch Deltaplan Dementie. WvdF holds the Pasman chair. The funding sources had no involvement in the writing of this article or in the decision to submit it for publications. JR acknowledges Prof Sergei Nazarenko, the North Estonia Medical Centre, and the International Atomic Energy Agency for their contribution to his professional development.

\section{Authors' contributions}

$\mathrm{JR}, \mathrm{RO}$, and FBo conceived the study, designed the protocol, analyzed/ interpreted the data, and drafted the manuscript. JR performed the statistical analysis. $\mathrm{RO}, \mathrm{FBo}$, and PS provided the overall study supervision. AdW, CET, $M Z, A D W, R B, F B a, W M v d F, P S$, and BNMvB had a major role in the acquisition of data and critically revised and edited the manuscript for intellectual content. All authors read and approved the final version of the manuscript.

\section{Funding}

Not applicable.

\section{Availability of data and materials}

The data used in this study are not publicly available but may be provided upon reasonable request.

\section{Ethics approval and consent to participate}

The local medical ethics committee of VU University Medical Center has approved a general protocol for biobanking and using the clinical data for research purposes

\section{Consent for publication}

Not applicable.

\section{Competing interests}

The authors declare that they have no competing interests.

\section{Author details}

${ }^{1}$ Department of Neurology \& Alzheimer Center Amsterdam, Amsterdam Neuroscience, Vrije Universiteit Amsterdam, Amsterdam UMC, P.O. Box 7057, 1007 MB Amsterdam, The Netherlands. '2Department of Health Technologies, Tallinn University of Technology, Tallinn, Estonia. ${ }^{3}$ Radiology Centre, North Estonia Medical Centre, Tallinn, Estonia. ${ }^{4}$ Neurochemistry Laboratory, Department of Clinical Chemistry, Amsterdam Neuroscience, Vrije Universiteit Amsterdam, Amsterdam UMC, Amsterdam, the Netherlands. ${ }^{5}$ Department of Radiology \& Nuclear Medicine, Amsterdam Neuroscience, Vrije Universiteit Amsterdam, Amsterdam UMC, Amsterdam, the Netherlands. ${ }^{6}$ Centre for Medical Image Computing, Medical Physics and Biomedical Engineering, UCL, London, UK. ${ }^{7}$ Department of Epidemiology \& Biostatistics, Amsterdam Neuroscience, Vrije Universiteit Amsterdam, Amsterdam UMC, Amsterdam, the Netherlands. ${ }^{8}$ Clinical Memory Research Unit, Lund University, Lund, Sweden.

Received: 18 June 2019 Accepted: 21 November 2019 Published online: 07 December 2019

\section{References}

1. Jansen WJ, Ossenkoppele R, Knol DL, Tijms BM, Scheltens P, Verhey FRJ, et al. Prevalence of cerebral amyloid pathology in persons without dementia: a meta-analysis. Jama. 2015;313:1924-38 Available from: http:// www.pubmedcentral.nih.gov/articlerender.fcgi?artid=4486209\&tool= pmcentrez\&rendertype=abstract.
2. Jack CR, Bennett DA, Blennow K, Carrillo MC, Dunn B, Haeberlein SB, et al. NIA-AA research framework: toward a biological definition of Alzheimer's disease. Alzheimer's Dement. 2018;14:535-62 Available from: https://doi.org/ 10.1016/j.jalz.2018.02.018.

3. Ikonomovic MD, Klunk WE, Abrahamson EE, Mathis CA, Price JC, Tsopelas ND, et al. Post-mortem correlates of in vivo PiB-PET amyloid imaging in a typical case of Alzheimer's disease. Brain. 2008;131:1630-45 Available from: https://academic.oup.com/brain/article-lookup/doi/10.1093/brain/awn016.

4. Sabri O, Sabbagh MN, Seibyl J, Barthel H, Akatsu H, Ouchi Y, et al. Florbetaben PET imaging to detect amyloid beta plaques in Alzheimer's disease: phase 3 study. Alzheimers Dement. 2015;11:964-74.

5. Curtis C, Gamez JE, Singh U, Sadowsky CH, Villena T, Sabbagh MN, et al. Phase 3 trial of flutemetamol labeled with radioactive fluorine 18 imaging and neuritic plaque density. JAMA Neurol. 2015;72:287-94.

6. Clark CM, Pontecorvo MJ, Beach TG, Bedell BJ, Coleman RE, Doraiswamy PM et al. Cerebral PET with florbetapir compared with neuropathology at autopsy for detection of neuritic amyloid- $\beta$ plaques: a prospective cohort study. Lancet Neurol. 2012;11:669-78 Available from: https://doi.org/10. 1016/S1474-4422(12)70142-4

7. Strozyk D, Blennow K, White LR, Launer LJ. CSF Abeta 42 levels correlate with amyloid-neuropathology in a population-based autopsy study. Neurology. 2003;60:652-6.

8. Sperling RA, Aisen PS, Beckett LA, Bennett DA, Craft S, Fagan AM, et al. Toward defining the preclinical stages of Alzheimer's disease: recommendations from the National Institute on Aging-Alzheimer's Association workgroups on diagnostic guidelines for Alzheimer's disease. Alzheimer's Dement. 2011;7:280 92 Available from: https://doi.org/10.1016/j.jalz.2011.03.003.

9. Dubois B, Feldman HH, Jacova C, Hampel H, Molinuevo JL, Blennow K, et al. Advancing research diagnostic criteria for Alzheimer's disease: the IWG-2 criteria. Lancet Neurol. 2014;13:614-29.

10. Albert MS, DeKosky ST, Dickson D, Dubois B, Feldman HH, Fox NC, et al. The diagnosis of mild cognitive impairment due to Alzheimer's disease: recommendations from the National Institute on Aging-Alzheimer's Association workgroups on diagnostic quidelines for Alzheimer's disease. Alzheimer's Dement. 2011;7:270-9 Available from: https://doi.org/10.1016/j.jalz.2011.03.008.

11. McKhann GM, Knopman DS, Chertkow H, Hyman BT, Jack CR, Kawas CH, et al. The diagnosis of dementia due to Alzheimer's disease: recommendations from the National Institute on Aging-Alzheimer's Association workgroups on diagnostic guidelines for Alzheimer's disease. Alzheimer's Dement. 2011;7:263-9 Available from: https://doi.org/10.1016/j. jalz.2011.03.005

12. Fagan AM. What does it mean to be "amyloid-positive"? Brain. 2015;138: 514-6 Available from: https://academic.oup.com/brain/article-lookup/doi/1 0.1093/brain/awu387.

13. Fagan AM, Mintun MA, Shah AR, Aldea P, Roe CM, Mach RH, et al. Cerebrospinal fluid tau and ptau181 increase with cortical amyloid deposition in cognitively normal individuals: implications for future clinical trials of Alzheimer's disease. EMBO Mol Med. 2009;1:371-80.

14. Zwan MD, Rinne JO, Hasselbalch SG, Nordberg A, Lleo A, Herukka SK, et al. Use of amyloid-PET to determine cutpoints for CSF markers: a multicenter study. Neurol Int. 2016;86:50-8 Available from: http://www.scopus.com/ inward/record.url?eid=2-s2.0-84952360236\&partnerlD=40\&md5= 63e500c4102f7bec04c2bb7ee968cb0b\%5Cnhttp://www.neurology.org/cgi/ doi/10.1212/WNL.0000000000002081\%5Cnhttp://ovidsp.tx.ovid.com/sp-3.18. ob/ovidweb.cgi?WebLinkFrameset=1\&S=IKPBF.

15. Blennow K, Mattsson N, Schöll M, Hansson O, Zetterberg H. Amyloid biomarkers in Alzheimer's disease. Trends Pharmacol Sci. 2015:36:297-309.

16. Arno de Wilde, Juhan Reimand, Charlotte E. Teunissen, Marissa Zwan, Albert D. Windhorst, Ronald Boellaard, Wiesje M. van der Flier, Philip Scheltens, Bart N.M. van Berckel, Femke Bouwman RO. Discordant amyloid- $\beta$ PET and CSF biomarkers and its clinical consequences (in press). Alzheimers Res Ther. 2019;11(1):78. https://doi.org/10.1186/s13195-019-0532-x

17. Mattsson N, Insel PS, Donohue M, Landau S, Jagust WJ, Shaw LM, et al. Independent information from cerebrospinal fluid amyloid- and florbetapir imaging in Alzheimer's disease. Brain. 2015;138:772-83 Available from: https://academic.oup.com/brain/article-lookup/doi/10.1093/brain/awu367.

18. Mielke MM, Wiste HJ, Weigand SD, Knopman DS, Lowe VJ, Roberts RO, et al. Indicators of amyloid burden in a population-based study of cognitively normal elderly. Neurology. 2012;79:1570-7.

19. Insel PS, Palmqvist S, Mackin RS, Nosheny RL, Hansson O, Weiner MW, et al. Assessing risk for preclinical $\beta$-amyloid pathology with APOE, cognitive, and 
demographic information. Alzheimer's Dement Diagnosis, Assess Dis Monit 2016;4:76-84. Available from: https://doi.org/10.1016/j.dadm.2016.07.002

20. ten Kate M, Redolfi A, Peira E, Bos I, Vos SJ, Vandenberghe R, et al. MRI predictors of amyloid pathology: results from the EMIF-AD Multimodal Biomarker Discovery study. Alzheimers Res Ther. 2018;10:100 Available from: http://www.ncbi.nlm.nih.gov/pubmed/30261928\%0Ahttps://alzres. biomedcentral.com/articles/10.1186/s13195-018-0428-1.

21. Li QX, Villemagne VL, Doecke JD, Rembach A, Sarros S, Varghese S, et al. Alzheimer's disease normative cerebrospinal fluid biomarkers validated in PET amyloid- $\beta$ characterized subjects from the Australian imaging, biomarkers and lifestyle (AIBL) study. J Alzheimers Dis. 2015;48:175-87.

22. Palmqvist $\mathrm{S}$, Mattsson N, Hansson O. Cerebrospinal fluid analysis detects cerebral amyloid- $\beta$ accumulation earlier than positron emission tomography. Brain. 2016;139:1226-36 Available from: https:/academic.oup. com/brain/article-lookup/doi/10.1093/brain/aww015.

23. Van Der Flier WM, Scheltens P. Amsterdam dementia cohort: performing research to optimize care. J Alzheimers Dis. 2018;62:1091-111.

24. Van Der Flier WM, Pijnenburg YAL, Prins N, Lemstra AW, Bouwman FH, Teunissen $C E$, et al. Optimizing patient care and research: the Amsterdam dementia cohort. J Alzheimers Dis. 2014;41:313-27.

25. McKhann G, Drachman D, Folstein M, Katzman R, Price D, Stadlan EM. Clinical diagnosis of Alzheimer's disease. Neurology. 1984;34:939-44.

26. Roman GC, Tatemichi TK, Erkinjuntti T, Cummings JL, Masdeu JC, Garcia JH, et al. Vascular dementia: diagnostic criteria for research studies: report of the NINDS-AIREN internal workshop. Neurology. 1993;43:250-60.

27. McKeith IG, Dickson DW, Lowe J, Emre M, O'Brien JT, Feldman H, et al. Diagnosis and management of dementia with Lewy bodies: third report of the DLB consortium. Neurology. 2005;65(12):1863-72.

28. Neary D, Snowden J, Gustafson L, Passant U, Stuss D, Black SE, et al. Frontotemporal lobar degeneration: a consensus on clinical diagnostic criteria. Neurol Int. 1998;51:1546-54 Available from: http://www.neurology. org/cgi/content/full/51/6/1546.

29. Gorno-Tempini M, Hillis AE, Weintraub S, Kertesz A, Mendez M, Cappa SF, et al. Classification of primary progressive aphasia and its variants. Neurologyogy. 2011;02:1006-14.

30. Litvan I, Agid Y, Calne D, Campbell G, Dubois B, Duvoisin RC, et al. Clinical research criteria for the diagnosis of progressive supranuclear palsy (SteeleRichardson-Olszewski syndrome): report of the NINDS-SPSP international workshop. Neurology. 1996;47:1-9.

31. Boeve BF, Lang AE, Litvan I. Corticobasal degeneration and its relationship to progressive supranuclear palsy and frontotemporal dementia. Ann Neurol. 2003;54:15-9.

32. Armstrong MJ, Litvan I, Lang AE, Bak TH, Bhatia KP, Borroni B, et al. Criteria for the diagnosis of corticobasal degeneration. Neurol Int. 2013;80:496-503 Available from: www.neurology.org.

33. Gilman S, Wenning GK, Low P a, Brooks DJ, Mathias CJ, Trojanowski JQ, et al. Second consensus statement on the diagnosis of multiple system atrophy. Neurology. 2008;71:670-6. Available from: http://www.ncbi.nlm.nih. gov/pubmed/18725592\%0Ahttp://www.pubmedcentral.nih.gov/ articlerender.fcgi?artid=PMC2676993

34. Groot C, Van Loenhoud AC, Barkhof F, Van Berckel BNM, Koene T, Teunissen CC, et al. Differential effects of cognitive reserve and brain reserve on cognition in Alzheimer disease. Neurology. 2018;90:e149-56.

35. Ossenkoppele R, Van Der Flier WM, Verfaillie SCJ, Vrenken H, Versteeg A, Van Schijndel RA, et al. Long-term effects of amyloid, hypometabolism, and atrophy on neuropsychological functions. Neurology. 2014;82:1768-75.

36. Engelborghs S, Niemantsverdriet E, Struyfs H, Blennow K, Brouns R, Comabella M, et al. Consensus guidelines for lumbar puncture in patients with neurological diseases. Alzheimer's Dement Diagnosis, Assess Dis Monit. 2017;8:111-26.

37. Schindler SE, Sutphen CL, Teunissen C, McCue LM, Morris JC, Holtzman DM, et al. Upward drift in cerebrospinal fluid amyloid $\beta 42$ assay values for more than 10 years. Alzheimer's Dement; 2018;14:62-70. Available from: https:// doi.org/10.1016/j.jalz.2017.06.2264

38. Tijms BM, Willemse EAJ, Zwan MD, Mulder SD, Visser PJ, Van Berckel BNM, et al. Unbiased approach to counteract upward drift in cerebrospinal fluid amyloid- $\beta$ 1-42 analysis results. Clin Chem. 2018;64:576-85.

39. de Wilde A, van Maurik IS, Kunneman M, Bouwman F, Zwan M, Willemse EAJ, et al. Alzheimer's biomarkers in daily practice project: rationale and design. Alzheimer's Dement Diagnosis, Assess Dis Monit. 2017;143-51. Available from: http://linkinghub.elsevier.com/retrieve/pii/ S2352872917300039
40. Verfaillie SCJ, Timmers T, Slot RER, van der Weijden CWJ, Wesselman LMP, Prins ND, et al. Amyloid- $\beta$ load is related to worries, but not to severity of cognitive complaints in individuals with subjective cognitive decline: the SCIENCe project. Front Aging Neurosci. 2019;11:1-9.

41. van Berckel BNM, Ossenkoppele R, Tolboom N, Yaqub M, Foster-Dingley JC, Windhorst AD, et al. Longitudinal amyloid imaging using 11C-PiB: methodologic considerations. J Nucl Med. 2013;54:1570-6 Available from: http://jnm.snmjournals.org/cgi/doi/10.2967/jnumed.112.113654.

42. Ossenkoppele R, Tolboom N, Foster-Dingley JC, Adriaanse SF, Boellaard R, Yaqub $\mathrm{M}$, et al. Longitudinal imaging of Alzheimer pathology using [11C]PIB, [18F]FDDNP and [18F]FDG PET. Eur J Nucl Med Mol Imaging. 2012; 39:990-1000.

43. Ossenkoppele R, Prins ND, Pijnenburg YAL, Lemstra AW, Van Der Flier WM, Adriaanse $\mathrm{SF}$, et al. Impact of molecular imaging on the diagnostic process in a memory clinic. Alzheimer's dement. 2013;9:414-21 Available from: https://doi.org/10.1016/j.jalz.2012.07.003.

44. de Wilde A, van der Flier WM, Pelkmans W, Bouwman F, Verwer J, Groot C, et al. Association of amyloid positron emission tomography with changes in diagnosis and patient treatment in an unselected memory clinic cohort. JAMA Neurol. 2018;75:1062-70 Available from: http://archneur.jamanetwork. com/article.aspx?doi=10.1001/jamaneurol.2018.1346.

45. Zwan MD, Bouwman FH, Konijnenberg E, van der Flier WM, Lammertsma $A A$, Verhey FRJ, et al. Diagnostic impact of [18F]flutemetamol PET in earlyonset dementia. Alzheimers Res Ther. 2017;9:2 Available from: http://alzres. biomedcentral.com/articles/10.1186/s13195-016-0228-4.

46. Koedam ELGE, Lehmann M, Van Der Flier WM, Scheltens P, Pijnenburg YAL, Fox N, et al. Visual assessment of posterior atrophy development of a MRI rating scale. Eur Radiol. 2011;21:2618-25.

47. Scheltens $P$, Leys $D$, Barkhof $F$, Huglo D, Weinstein HC, Vermersch $P$, et al. Atrophy of medial temporal lobes on MRI in "probable" Alzheimer's disease and normal ageing: diagnostic value and neuropsychological correlates. J Neurol Neurosurg Psychiatry. 1992;55:967-72.

48. Fazekas F, Chawluk JB, Alavi A, Hurtig HIZR. MR signal abnormalities at $1.5 \mathrm{~T}$ in Alzheimer's dementia and normal aging deficiency. AJR Am J Roentgenol. 1987;149:351-6.

49. Jessen $F$, Amariglio RE, van Boxtel M, Breteler M, Ceccaldi M, Chételat G, et al. A conceptual framework for research on subjective cognitive decline in preclinical Alzheimer's disease. Alzheimers Dement. 2014;10:844-52 Available from: http://www.pubmedcentral.nih.gov/articlerender.fcgi?artid= 4317324\&tool=pmcentrez\&rendertype $=$ abstract.

50. R Core Team. R: a language and environment for statistical computing. Vienna, Austria: R Foundation for Statistical Computing; 2018. p. https:// www.R-project.org/.

51. van Buuren S, Groothuis-Oudshoorn K. mice: Multivariate imputation by chained equations in R. J Stat Softw. 2011;45(3). https://doi.org/10.18637/jss. v045.103.

52. Breiman L. Random forests. Mach Learn. 2001;45:5-32.

53. Strobl C, Boulesteix AL, Kneib T, Augustin T, Zeileis A. Conditional variable importance for random forests. BMC Bioinformatics. 2008;9:1-11.

54. Breiman OEL, Berkeley C. Out-of-bag estimation; 1996.

55. Janitza S, Strobl C. An AUC-based permutation variable importance measure for random forests an AUC-based permutation variable importance measure for random forests; 2012.

56. Strobl C, Boulesteix AL, Zeileis A, Hothorn T. Bias in random forest variable importance measures: illustrations, sources and a solution. BMC Bioinformatics. 2007;8:25.

57. Burnham K, Anderson D. Model selection and multimodel inference: a practical information-theoretic approach, second edition. Ecol Model 2002. ISBN: 978-0-387-22456-5.

58. Hochberg B. Controlling the false discovery rate: a practical and powerful approach to multiple testing. J R Stat Soc. 1995;57:289-300 Available from: http://www.jstor.org/stable/2346101.

59. Wiltfang J, Esselmann H, Bibl M, Hüll M, Hampel H, Kessler H, et al. Amyloid $\beta$ peptide ratio $42 / 40$ but not $A \beta 42$ correlates with phospho-Tau in patients with low- and high-CSF Aß40 load. J Neurochem. 2007;101:1053-9.

60. Cairns NJ, Ikonomovic MD, Benzinger T, Fagan AM, Shah A, Schmidt RE, et al. Absence of Plttsburgh compound B detection of cerebral amyloid Beta in a patient with clinical, cognitive, and cerebrospinal fluid markers of Alzheimer disease. Arch Neurol. 2009;66:1557-62.

61. Qiang W, Yau W-M, Lu J-X, Collinge J, Tycko R. Structural variation in amyloid- $\beta$ fibrils from Alzheimer's disease clinical subtypes. Nature. 2017; 
541:217-21 Available from: http://www.nature.com/doifinder/10.1038/ nature20814.

62. Hansson O, Mikulskis A, Fagan AM, Teunissen C, Zetterberg H, Vanderstichele $\mathrm{H}$, et al. The impact of preanalytical variables on measuring cerebrospinal fluid biomarkers for Alzheimer's disease diagnosis: a review. Alzheimer's Dement. 2018:1313-33 Available from: https://doi.org/10.1016/j. jalz.2018.05.008

63. Vos SJB, Visser PJ, Verhey F, Aalten P, Knol D, Ramakers I, et al. Variability of CSF alzheimer's disease biomarkers: implications for clinical practice. PLoS One. 2014;9:e100784.

64. Mattsson N, Insel PS, Donohue M, Landau S, Jagust WJ, Shaw LM, et al. Independent information from cerebrospinal fluid amyloid-b and florbetapir imaging in Alzheimer's disease. Brain. 2015;138(3):772-83.

65. Blennow K, Wallin A, Agren H. tau protein in cerebrospinal fluid. A biochemical marker. Mol Chem Neuropathol. 1995;26:231-45.

66. Seppälä TT, Koivisto AM, Hartikainen P, Helisalmi S, Soininen H, Herukka SK. Longitudinal changes of CSF biomarkers in Alzheimer's disease. J Alzheimers Dis. 2011;25:583-94.

67. Wildsmith KR, Schauer SP, Smith AM, Arnott D, Zhu Y, Haznedar J, et al. Identification of longitudinally dynamic biomarkers in Alzheimer's disease cerebrospinal fluid by targeted proteomics. Mol Neurodegener. 2014;9:1-14.

68. Fagan AM, Xiong C, Jasielec MS, Bateman RJ, Goate AM, Benzinger TLS, et al. Longitudinal change in CSF biomarkers in autosomal-dominant Alzheimer's disease. Sci Transl Med. 2014;6:226ra30 Available from: http:// www.tandfonline.com/doi/abs/10.1081/AL-120016110.

69. Olsson B, Lautner R, Andreasson U, Öhrfelt A, Portelius E, Bjerke M, et al. CSF and blood biomarkers for the diagnosis of Alzheimer's disease: a systematic review and meta-analysis. Lancet Neurol. 2016;15:673-84.

70. Reiman EM, Chen K, Liu X, Bandy D, Yu M, Lee W, et al. Fibrillar amyloidburden in cognitively normal people at 3 levels of genetic risk for Alzheimer's disease. Proc Natl Acad Sci. 2009;106:6820-5 Available from: http://www.pnas.org/cgi/doi/10.1073/pnas.0900345106.

71. Mattsson N, Groot C, Jansen WJ, Landau SM, Villemagne VL, Engelborghs S, et al. Prevalence of the apolipoprotein $E \varepsilon 4$ allele in amyloid $\beta$ positive subjects across the spectrum of Alzheimer's disease. Alzheimers Dement. 2018;14:913-24.

72. Braak H, Braak E. Neuropathological stageing of Alzheimer-related changes. Acta Neuropathol. 1991;82:239-59.

73. Jack CR, Holtzman DM. Biomarker modeling of Alzheimer's disease. Neuron. 2013;80:1347-58 Available from: https://doi.org/10.1016/j.neuron.2013.12. 003.

74. Niemantsverdriet E, Ottoy J, Somers C, De Roeck E, Struyfs H, Soetewey F, et al. The cerebrospinal fluid AB1-42/Aß1-40 Ratio improves concordance with amyloid-PET for diagnosing Alzheimer's disease in a clinical setting. J Alzheimers Dis. 2017;60:561-76.

75. Lewczuk P, Matzen A, Blennow K, Parnetti L, Molinuevo JL, Eusebi P, et al. Cerebrospinal fluid $A \beta 42 / 40$ Corresponds better than $A \beta 42$ to amyloid PET in Alzheimer's disease. J Alzheimers Dis. 2017;55:813-22.

\section{Publisher's Note}

Springer Nature remains neutral with regard to jurisdictional claims in published maps and institutional affiliations.

Ready to submit your research? Choose BMC and benefit from:
- fast, convenient online submission
- thorough peer review by experienced researchers in your field
- rapid publication on acceptance
- support for research data, including large and complex data types
- gold Open Access which fosters wider collaboration and increased citations
- maximum visibility for your research: over 100M website views per year
At BMC, research is always in progress.
Learn more biomedcentral.com/submissions

